\title{
TRANSCRIPCIÓN TEXTO DE LECCIONES DEL PROFESOR JORGE MILLAS ${ }^{1}$
}

\begin{abstract}
$\widehat{R A}$ “... de sistematizarlas y de convertirlas en experiencia de reflexión, depende en gran parte su efectividad; de que haya, en efecto, una integración participativa, que ayuda, efectivamente, a desarrollar esa experiencia reflexiva, que es la que puede ser la única base posible para asimilar la filosofía como vivencia, que es lo realmente importante. Ya que, como ustedes lo van a ir viendo, la filosofía no se puede aprender, en el sentido de manejarla mediante esquemas, mediante instrucciones. Lo que se puede es desarrollar la actitud filosófica; actitud que, claro, requiere de algunos instrumentos técnicos, pero que son secundarios, porque son realmente inútiles y no se apoyan realmente, primero, en la vivencia del problema - poder vivir el problema como auténtica sorpresa- $y$, en segundo lugar, en la experiencia -no menos vivida- de poder salir al encuentro de esa sorpresa, con nuevas reflexiones, que conducen a nuevas sorpresas, pero que, de todas maneras, adelantan un camino.
\end{abstract}

Eso es lo que estoy tratando de demostrar a través del curso y, para continuar con nuestra ruta, yo quisiera que nos representáramos otra vez a ese aparentemente desvalido ser humano a quien hemos venido encerrando ya a lo largo de dos lecciones en este calabozo de su conciencia, del cual no escapa porque solo dispone de unas ventanillas de observación, de unas ventanillas de contacto con lo real, que es esporádico, que es incidental, que es básico, como hemos dicho; la visión de esto, la omisión de lo otro, tal o cual vivencia, y que inmediatamente se extinguen porque el tiempo transcurre.

Sin embargo, nosotros no nos sentimos así; nosotros nos sentimos con un ancho mundo a nuestra merced. En él nos movemos y nos parece que, en efecto, tenemos un amplio, riquísimo, contacto con lo real. Y este parecer es el que realmente nos ayuda a vivir. Sin embargo, no invalida el análisis que hemos hecho anteriormente.

En efecto, el único encuentro de la conciencia con lo real es el que ocurre en el instante y el aquí. Pero, de una manera natural y normal, se va produciendo la integración de la experiencia. Esta secuencia de vivencias aisladas, sucesivas, va constituyendo una unidad, va constituyendo un flujo; y ya lo vimos cómo - con el auxilio de la memoria-, se van, como quien dice, ensartando en un hilo de continuidad los diferentes momentos de nuestra experiencia. Pero, al mismo tiempo se va produciendo, porque a partir de esta memoria recogida y concentrada por la memoria, nuestra conciencia se proyecta hacia el futuro, hacia el instante inmediato, o hacia un tiempo de mayor duración, mediante la

El audio de esta clase, del que esta transcripción es solo un fragmento, lo puede usted escuchar desde el sitio web de la revista: https://revistafilosofia.uchile.cl 
expectativa. Y esta expectativa está regida desde la memoria por la experiencia pasada, y espera verificación, espera cumplimiento en el paso que sigue, porque es que decíamos que toda percepción -para tomar el caso más simple con lo real que es la percepción-, toda percepción es como el signo, o el anuncio, o la promesa de nuevas percepciones.

Eso es lo que significaba para nosotros la naranja, que ahora se nos ha convertido en manzana. Significaba percibir la manzana; no solo incorporar esa percepción a un continuo de percepciones exteriores mediante la memoria, sino también prever o anticipar posibles experiencias: la de gustar esta manzana, por ejemplo, o la de utilizarla de cualquiera manera. Hay, entonces, un paso de la experiencia aislada que nos encierra, hacia una expansión de nuestro horizonte, en virtud de la memoria que acumula vivencias anteriores y de la expectativa de desarrollo que nuestras vivencias actuales nos ofrecen.

Estas cosas, que el análisis contemporáneo -por intentar ser más completopuede complicar un poco, habían sido, en realidad, entrevistas, de una manera bastante sagaz, y expresadas en términos muy simples por antiguos pensadores, entre los cuales podemos elegir a uno de las más antiguos y eminentes, a Aristóteles, nada menos, quien deja registrado en una de sus obras la siguiente observación -y vean ustedes que simple es y como se carga de sentido para nosotros después de haber pasado por este largo análisis: "De la sensación -dice Aristóteles- viene lo que llamamos memoria, y del recuerdo muchas veces repetido de una misma cosa, formamos lo que llamamos experiencia, pues una multiplicidad numérica de recuerdos constituye una sola experiencia”. De manera que aquí está dejando constancia Aristóteles de que eso que llamamos experiencia no es una vivencia de totalidad, sino que es una reconstrucción, o reconstitución, mediante la memoria.

El análisis de Aristóteles habría que completarlo solamente mostrando este otro aspecto, el aspecto ya no retrospectivo de la experiencia, sino el aspecto proyectivo de ella. Porque tener una experiencia no es solo recoger lo vivido, en el tracto sucesivo del tiempo, sino, al mismo tiempo, sino, a la vez, predisponerse hacia el desarrollo de vivencias futuras; de manera que la experiencia auténtica es dinámica, en el sentido de que recoge el pasado y se proyecta hacia el futuro como expectativa. Nunca una experiencia es muerte. Una experiencia siempre es un conato de acción. Una experiencia predispone a la actividad. Y en el caso tan simple que estamos considerando, de la acumulación de estas formas elementales de experiencia, que son nuestras percepciones, eso también tiene efectividad. El entender esto como manzana, que es realmente percibirlo, implica preparar actos posibles, preparar todo un esquema de actividad, que va a ser distinto si yo percibiera esto como un serrucho. Entonces, hay una predisposición a actuar a través de mi acumulación de experiencias instantáneas.

Ustedes ven que, de este modo, se va produciendo una suerte de integración natural de la experiencia. El prisionero de la conciencia va escapando a su calabozo, va recogiendo muchas vivencias, las va incorporando en secuencias estructuradas en su conciencia y, al mismo tiempo, va anticipándose a experiencias futuras. Esto es lo importante: "anticipándose a experiencias futuras", mediante la expectativa que a partir de la experiencia presente se le crean. Yo, en realidad, estoy integrando el 
pasado, a través del presente, con el futuro, cuando - percibiendo este objeto-reconozco que es una manzana. El reconocer que es una manzana implica movilizar todas mis experiencias anteriores a través de la memoria, y de ese aspecto activo reflejo que tiene la memoria en el hábito movilizo yo mi memoria, movilizo mis hábitos; pero, al mismo tiempo, anticipo experiencias futuras. De tal modo que estoy, incluso, proyectando mi experiencia más allá de lo actual y anticipándome al desarrollo que va a venir. Estoy, prácticamente, prediciendo el curso futuro de la experiencia ...”.

Transcripción de RAÚL VILLARROEL

Universidad de Chile rvillarr@uchile.cl 